\title{
Brief
}

\section{Percutaneous treatment of a ruptured intercostal aneurysm presenting as massive hemothorax in a patient with type I neurofibromatosis}

\author{
J. Dominguez, MD, ${ }^{a}$ C. Sancho, MD, ${ }^{a}$ E. Escalante, MD, ${ }^{a}$ J. R. Morera, MD, ${ }^{b}$ J. A. Moya, MD, ${ }^{b}$ and R. Bernat, MD, ${ }^{c}$ \\ Barcelona, Spain
}

From the Departments of Vascular Radiology, ${ }^{\text {a }}$ Thoracic Surgery, ${ }^{\mathrm{b}}$ and Pathology, Hospital "Princeps d'Espanya," Barcelona, Spain.

Received for publication Feb 7, 2002; accepted for publication Feb 18, 2002.

Address for reprints: Department de Radiologia Vascular, Hospital "Princeps d'Espanya," Feixa Llarga s/n, 08907L'Hospitalet de Llobregat, Barcelona, Spain.

J Thorac Cardiovasc Surg 2002;124:1230-2

Copyright $\odot 2002$ by The American Association for Thoracic Surgery

$0022-5223 / 2002 \$ 35.00+0 \quad \mathbf{1 2 / 5 4 / 1 2 4 2 6 4}$

doi: $10.1067 / \mathrm{mtc} .2002 .124264$

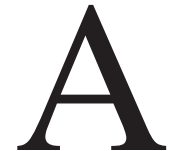

cute hemothorax caused by intercostal artery aneurysm rupture is a life-threatening complication of type I neurofibromatosis (NF I), which was successfully treated with percutaneous embolization.

\section{Clinical Summary}

A 44-year-old man with NF I had sudden pleuritic pain and dyspnea 36 hours before admission to our hospital. Previously, he had been admitted to another center, where massive hematic pleural effusion was detected, and chest tube drainage yielded $1800 \mathrm{~mL}$ of blood. There was no past history of trauma, surgical intervention, or rib fracture.

On arrival at our hospital, the patient was conscious and had an arterial pressure of 114/69 $\mathrm{mm} \mathrm{Hg}$, a heart rate of 120 beats/min, an oxygen saturation of $92 \%$, a hematocrit value of $21 \%$, and a hemoglobin value of $7.1 \mathrm{~g} / \mathrm{dL}$. The chest $\mathrm{x}$-ray film showed massive left pleural effusion and severe high dorsal scoliosis (Figure 1). Auscultation revealed left hemithorax hypophonesis.

Because of the severity of the clinical picture, thoracic aortography was urgently performed, and a lesion suspected to be aneurysmal was detected in the upper third of the left hemithorax. A 5-mL total volume of low osmolality contrast medium at a rate of $1 \mathrm{~mL} / \mathrm{s}$ was selectively injected into the fourth left intercostal artery with a multipurpose $5 \mathrm{~F}$ catheter (Biosphere Medical, Louvres, France), confirming the presence of a 1-cm-diameter aneurysm located $2 \mathrm{~cm}$ from the ostium (Figure 2, A). At the end of the injection, extravasation was observed at the site of the ruptured aneurysm (Figure 2, B).

Subsequently, we performed therapeutic embolization of the hemorrhagic lesion, attempting to occlude the artery proximal and distal to the aneurysm. However, because of difficulties in advancing the guide wire (Terumo Europe, Leuven, Belgium) past the aneurysm, we had to occlude the aneurysmal sac itself with one 6/300 platinum coil (Balt, Montmorency, France) and one 35/6-3 “Tornado" coil (Cook Europe, Bjaeverskov, Denmark). Three 35-1-3 Gianturco coils (Cook Europe) were then added in the short proximal arterial segment. All the coils were delivered through the multipurpose catheter. Arteriography confirmed the exclusion of the lesion and the absence of other potential bleeding foci in the thorax (Figure 3).

The patient's clinical evolution after embolization was good. At 3 days, the hematocrit level had recuperated to $38 \%$. However, the chest radiographic features did not improve, and surgical intervention for pleural debridement and withdrawal of clots of the organized hemothorax was decided. During the operation, after removal of the clotted blood, bleeding was detected at several points in the hypervascularized fungous tissue adjacent to the embolized aneurysm and occupying the apical and left upper paravertebral regions.

Histologic study of a fragment of tissue adjacent to the aneurysm identified pseudoneoplastic mesenchymal proliferation that tested positive for CD34 and S100 markers, which is consistent with the diagnosis of neurofibroma plexiforme without atypia.

The patient was discharged from the hospital 10 days later, after a favorable postoperative period, and remains free of symptoms at 19 months. 


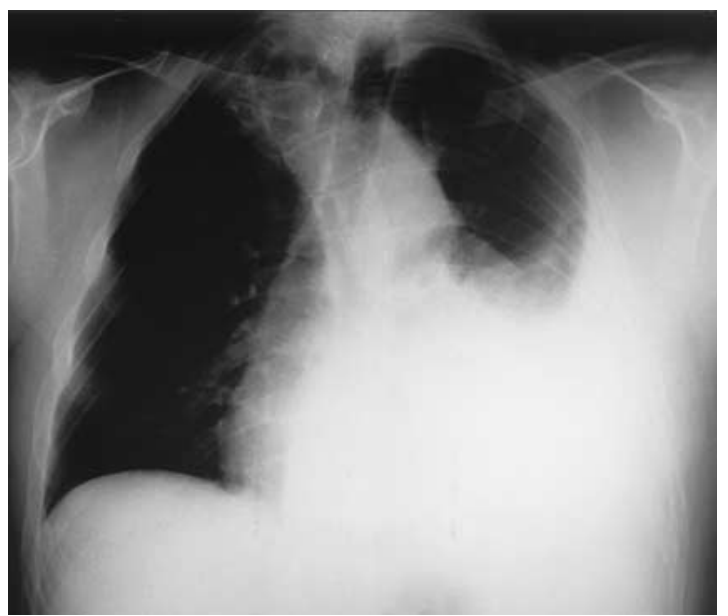

Figure 1. Posteroanterior plain chest film shows massive left pleural effusion and severe high dorsal scoliosis.

\section{Discussion}

Von Recklinghausen disease or NF I is a hereditary autosomal dominant disorder originating in the neuroectoderm and mesoderm. It is expressed in approximately $80 \%$ of those who have the gene, and it has an incidence of about 1:3000. NF I is characterized by abnormal cutaneous pigmentation and multiple skin tumors, and it is frequently associated with scoliosis and other skeletal abnormalities. The incidence of vascular lesions has been reported to be only $3.6 \%$, mostly vascular stenoses and aneurysms.

In addition to the present case, the literature contains 22 other cases of massive intrathoracic hemorrhage in patients with NF I, ${ }^{1-9}$ including a series of 12 cases reported by Miura and colleagues ${ }^{3}$ in Japan. Only 2 presented as hemomediastinum, ${ }^{7,9}$ and the others presented as hemothorax. ${ }^{1-6,8}$

The causes described in these cases are diverse and can be divided into 2 groups: bleeding by vascularized tumors of mesenchymal origin, such as ganglioneuromas or neurofibromas, ${ }^{1,2,8}$ and bleeding caused by rupture of weak medium- to large-caliber arteries. ${ }^{2-7,9}$ According to Greene and coworkers, ${ }^{10}$ these arteries are either surrounded by neurofibromatous or ganglioneuromatous tissue or have weak walls caused by intimal proliferation, thinning of the muscle layer, and fragmentation of the elastic layer, making them susceptible to formation of aneurysms.

The arteries where bleeding originates are located in the mediastinum, in the region of the thoracic cage or in the diaphragm. The subclavian ( 7 cases) or intercostal (6 cases) arteries are most often affected, but other affected arteries, including the tyrocervical trunk, the internal thoracic artery, the phrenic artery, and the left vertebral artery arising directly from the aorta, have also been reported.

Initially, the bleeding is extrapleural, but it does not remain confined to this space; the pleura ruptures, and a massive hemothorax develops. ${ }^{2}$ The proximity to vertebral segments with severe scoliosis has suggested, in some cases, the implication of mechanical factors in the triggering of arterial rupture..$^{2,11}$

Aneurysms in NF I have been described in all the vascular territories ${ }^{11-18}$ and are usually of the saccular type. Thread-like aneurysms are infrequent and are often poststenotic. ${ }^{14}$
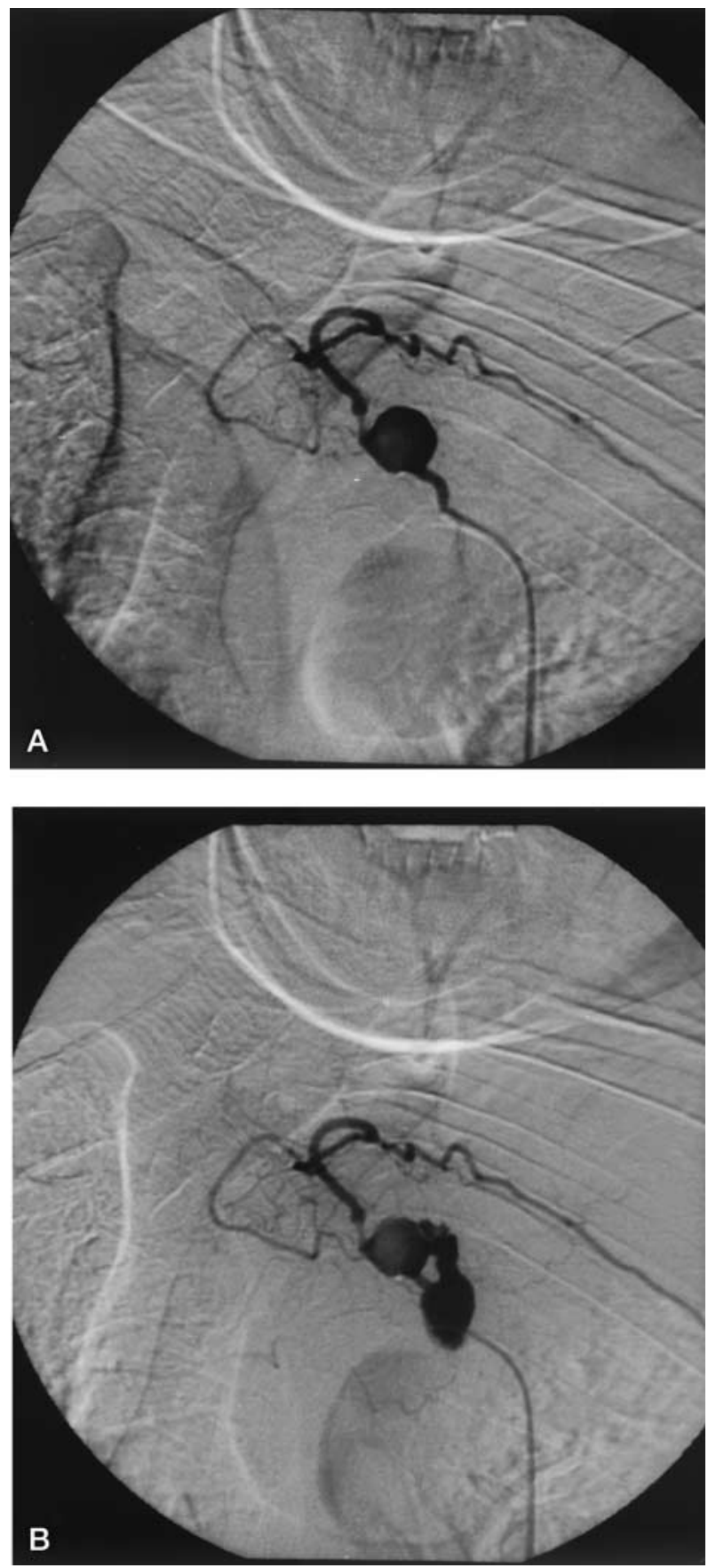

Figure 2. A, Selective injection in the fourth left intercostal artery demonstrates the aneurysm. B, Spilling out of contrast, revealing the origin of the hemorrhage (arrow).

Samples of the aneurysm were not obtained in our case, but the adjacent tissue was described during the operation as fungous and easy bleeding material. After histologic examination, the tissue was described as "pseudoneoplastic mesenchymal proliferation, consistent with the diagnosis of neurofibroma."

Regarding the development of the diagnostic and therapeutic process, we highlight the importance of fast action once the 




Figure 3. Aortography after embolization shows occlusion of the aneurysm with coils (arrow).

hemothorax is detected, in spite of transitory stable intervals that might mask the severity of the situation. ${ }^{3}$ When clinical signs suggest acute massive bleeding, which has been localized, confirmed by diagnostic puncture in the pleural space, arteriography should be carried out to determine the position of the lesion. The options for hemostasia by the percutaneous route, whether through embolization or covered prosthesis, should then be considered according to the caliber of the vessel and the collateral circulation.

When feasible, sandwich aneurysm embolization is faster and cheaper than filling the cavity with multiple coils. ${ }^{5}$ In this case the difficulty in progressing the guide wire beyond the aneurysm, along with the knowledge of vascular fragility in this type of lesion, compelled us to use the second option. Obviously, sealing of the bleeding focus should always precede hemothorax decompression with a chest tube to avoid quick exsanguination..$^{1,3}$

Surgical repair is aggressive and complex, and reconstruction of vessels is limited by arterial fragility. ${ }^{12}$ We believe surgical intervention should be a second option for use when percutaneous treatment is not totally effective. An operation can also be used as complementary therapy, as in the case of our patient, who required decompression of the lung constricted by the hematoma.

Finally, prevention of the vascular complications in NF I is highly desirable, more because of severity of complications than frequency. Various diagnostic methods can be used for the screening and periodic control of large- and medium-caliber vessels, including Doppler echocardiography, magnetic resonance angiography, and computed tomographic angiography. ${ }^{13}$

\section{References}

1. Larrieu AJ, Hashimoto SA, Allen P. Spontaneous massive haemothorax in von Recklinghausen's disease. Thorax. 1982;37:151-2.

2. Butchart EG, Grötte GJ, Barnsley WC. Spontaneous rupture of an intercostal artery in a patient with neurofibromatosis and scoliosis. J Thorac Cardiovasc Surg. 1975;69:919-21.

3. Miura H, Taira O, Uchida O, Usuda J, Hirai S, Kato H. Spontaneous haemothorax associated with von Recklinghausen's disease: review of occurrence in Japan. Thorax. 1997;52:577-8.

4. Brady DB, Bolan JC. Neurofibromatosis and spontaneous hemothorax in pregnancy: two case reports. Obstet Gynecol. 1984;63:35S-8S.

5. Teitelbaum GP, Hurvitz RJ, Esrig BC. Hemothorax in type I neurofibromatosis. Ann Thorac Surg. 1998;66:569-71.

6. Griffiths AP, White J, Dawson A. Spontaneous haemothorax: a cause of sudden death in von Recklinghausen's disease. Postgrad Med J. 1998;74:679-81.

7. Magara T, Onoe M, Yamamoto Y, Kawakami K, Hirai T, Matsumoto M. Massive mediastinal bleeding due to spontaneous rupture of the vertebral artery in von Recklinghausen's disease. Jpn J Thorac Cardiovasc Surg. 1998;46:906-9.

8. Fuyuno G, Kobayashi R, Iga R, Horio H, Nomori H, Kodera K, et al. A case of von Recklinghausen's disease associated with a hemothorax due to a rapidly growing malignant schwannoma. Jpn J Thorac Dis. 1995;33:682-5.

9. Leier CV, DeWan ChJ, Anatasia LF. Fatal hemorrhage as a complication of neurofibromatosis. Vasc Surg. 1972;6:98-101.

10. Greene JF, Fitzwater JE, Burgess J. Arterial lesions associated with neurofibromatosis. Am J Clin Pathol. 1974;62:481-7.

11. Horsley M, Taylor TK, Sorby WA. Traction-induced rupture of an extracranial vertebral artery aneurysm associated with neurofibromatosis. Spine. 1997;22:225-7.

12. Saitoh S, Matsuda S. Aneurysm of the major vessels in neurofibromatosis. Arch Orthop Trauma Surg. 1998;117:110-3.

13. Cormier JM, Cormier F, Mayade J, Fichelle JM. Complications arterielles de la neurofibromatose. J Mal Vasc. 1999;24:281-6.

14. Hassen-Khodja R, Declemy S, Batt M, Castanet J, Perrin C, Ortonne JP, et al. Visceral artery aneurysms in Von Recklinghausen's neurofibromatosis. J Vasc Surg. 1997;25:572-5.

15. Hoffmann KT, Hosten N, Liebig T, Schwarz K, Felix R. Giant aneurysm of the vertebral artery in neurofibromatosis type 1: report of a case and review of the literature. Neuroradiology. 1998;40:245-8.

16. Ushikoshi S, Goto K, Uda K, Ogata N, Takeno Y. Vertebral arteriovenous fistula that developed in the same place as a previous ruptured aneurysm: a case report. Surg Neurol. 1999;51:168-73.

17. Ilgit ET, Vural M, Oguz A, Ozdogan ME. Peripheral arterial involvement in neurofibromatosis type I: a case report. Angiology. 1999;50: 955-8.

18. Grey AC, Vallelly SR. Spontaneous false aneurysm of the radial artery in neurofibromatosis. Clin Radiol. 1999;54:185-96. 